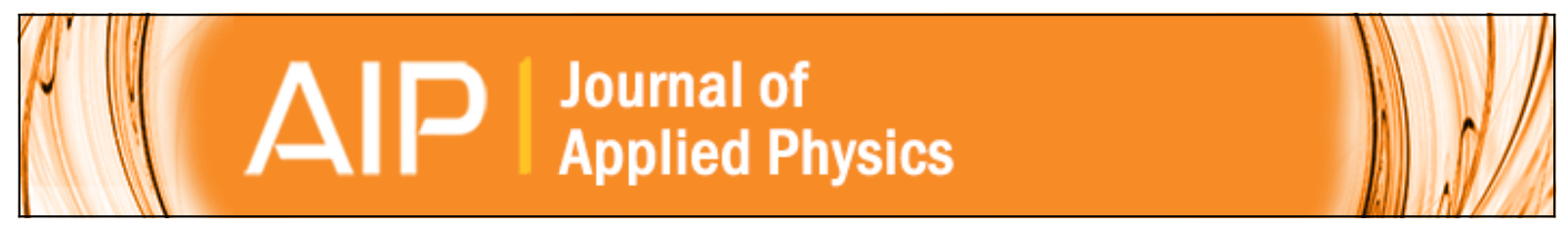

\title{
Hydrogen effusion from tritiated amorphous silicon
}

N. P. Kherani, B. Liu, K. Virk, T. Kosteski, F. Gaspari, W. T. Shmayda, S. Zukotynski, and K. P. Chen

Citation: Journal of Applied Physics 103, 024906 (2008); doi: 10.1063/1.2831495

View online: http://dx.doi.org/10.1063/1.2831495

View Table of Contents: http://scitation.aip.org/content/aip/journal/jap/103/2?ver=pdfcov

Published by the AIP Publishing

\section{Articles you may be interested in}

Improved conductivity of aluminum-doped $\mathrm{ZnO}$ : The effect of hydrogen diffusion from a hydrogenated amorphous silicon capping layer

J. Appl. Phys. 111, 063715 (2012); 10.1063/1.3692439

Hydrogenated amorphous silicon deposited under accurately controlled ion bombardment using pulse-shaped substrate biasing

J. Appl. Phys. 108, 103304 (2010); 10.1063/1.3505794

Metal induced hydrogen effusion from amorphous silicon

Appl. Phys. Lett. 91, 241901 (2007); 10.1063/1.2819086

Nanostructure evolution in hydrogenated amorphous silicon during hydrogen effusion and crystallization

Appl. Phys. Lett. 90, 081923 (2007); 10.1063/1.2435959

Hydrogen configurations and stability in amorphous sputtered silicon

J. Appl. Phys. 81, 3073 (1997); 10.1063/1.364321

\section{AlP Re-register for Table of Content Alerts}

\section{Create a profile.

 \\ Sign up today!}




\title{
Hydrogen effusion from tritiated amorphous silicon
}

\author{
N. P. Kherani, ${ }^{1, a)}$ B. Liu, ${ }^{2}$ K. Virk, ${ }^{1}$ T. Kosteski, ${ }^{1}$ F. Gaspari, ${ }^{1}$ W. T. Shmayda, ${ }^{3}$ \\ S. Zukotynski, ${ }^{1}$ and K. P. Chen ${ }^{2}$ \\ ${ }^{1}$ Department of Electrical and Computer Engineering, University of Toronto, \\ Toronto, Ontario M5S 3G4, Canada \\ ${ }^{2}$ Department of Electrical and Computer Engineering, University of Pittsburgh, \\ Pittsburgh, Pennsylvania 15261, USA \\ ${ }^{3}$ Laboratory for Laser Energetics, University of Rochester, Rochester, New York 14623-1299, USA
}

(Received 4 December 2006; accepted 14 November 2007; published online 17 January 2008)

\begin{abstract}
Results for the effusion and outgassing of tritium from tritiated hydrogenated amorphous silicon $(a-\mathrm{Si}: \mathrm{H}: \mathrm{T})$ films are presented. The samples were grown by dc-saddle field glow discharge at various substrate temperatures between 150 and $300{ }^{\circ} \mathrm{C}$. The tracer property of radioactive tritium is used to detect tritium release. Tritium effusion measurements are performed in a nonvacuum ion chamber and are found to yield similar results as reported for standard high vacuum technique. The results suggest for decreasing substrate temperature the growth of material with an increasing concentration of voids. These data are corroborated by analysis of infrared absorption data in terms of microstructure parameters. For material of low substrate temperature (and high void concentration) tritium outgassing in air at room temperature was studied, and it was found that after $600 \mathrm{~h}$ about $0.2 \%$ of the total hydrogen (hydrogen + tritium) content is released. Two rate limiting processes are identified. The first process, fast tritium outgassing with a time constant of $15 \mathrm{~h}$, seems to be related to surface desorption of tritiated water (HTO) with a free energy of desorption of $1.04 \mathrm{eV}$. The second process, slow tritium outgassing with a time constant of 200-300 h, appears to be limited by oxygen diffusivity in a growing oxide layer. This material of lowest $\mathrm{H}$ stability would lose half of the hydrogen after 60 years. (C) 2008 American Institute of Physics. [DOI: $10.1063 / 1.2831495$ ]
\end{abstract}

\section{INTRODUCTION}

Hydrogenated amorphous silicon $(a-\mathrm{Si}: \mathrm{H})$ has been the subject of much attention for the last 30 years owing to the importance of understanding the properties of amorphous semiconductors and its significance for large area optoelectronic and photovoltaic applications. ${ }^{1}$ Since the demonstration of semiconductor properties of $a$-Si: $\mathrm{H}^{2,3}$ many studies have been carried out to understand the structure of $a-\mathrm{Si}: \mathrm{H}$ and to gain insight into the incorporation of hydrogen into this material. Some of the techniques used in these studies include Fourier transform infrared (FTIR) spectroscopy and hydrogen effusion experiments. ${ }^{4-6}$

FTIR absorption of the modes introduced by tritium $\left({ }^{3} \mathrm{H}\right.$, an isotope of hydrogen) in amorphous silicon $(a-\mathrm{Si})$ has been studied. ${ }^{7-9}$ The effects of radioactive decay of tritium on device and optoelectronic properties of tritiated hydrogenated amorphous silicon $(a-\mathrm{Si}: \mathrm{H}: \mathrm{T})$ have been examined. ${ }^{10-13}$ The incorporation of tritium in $a-\mathrm{Si}: \mathrm{H}$ has been proposed for niche micropower applications. ${ }^{14,15}$ The basic forms of these applications are self-powered radioluminescent structures and betavoltaic devices. ${ }^{16,17}$

Due to the emission of an energetic electron upon radioactive decay of tritium, tritium can be detected using simple methods at much lower levels than the nonradioactive isotopes of hydrogen. ${ }^{18,19}$ Using this radiotracer property of tritium, this paper presents experimental data on the evolution

\footnotetext{
${ }^{a)}$ Electronic mail: kherani@ecf.utoronto.ca.
}

of tritium from tritiated hydrogenated amorphous silicon $(a-\mathrm{Si}: \mathrm{H}: \mathrm{T})$. Tritium concentration in the $a-\mathrm{Si}: \mathrm{H}: \mathrm{T}$ films is determined using thermal desorption and FTIR methods. Thermal effusion of tritium and FTIR spectroscopy data are used to infer the structural characteristics of $a-\mathrm{Si}: \mathrm{H}: \mathrm{T}$ films. Long-term tritium outgassing in air at room temperature is analyzed to provide information on the kinetics of surface desorption and diffusion limited hydrogen evolution, from which the free energy of desorption of tritiated water (HTO) and diffusion coefficient of oxygen are estimated.

\section{EXPERIMENT}

\section{A. Sample preparation}

The $a-\mathrm{Si}: \mathrm{H}: \mathrm{T}$ films, deposited on crystalline silicon wafers, were prepared in a dc-saddle field glow discharge deposition chamber. The deposition facility and the procedure followed are described elsewhere. ${ }^{10,11}$ The depositions reported here involved the flow of pure silane and tritium gases through the glow discharge chamber at 2.5 SCCM (SCCM denotes cubic centimeter per minute at STP) each and a chamber pressure of $50 \mathrm{mTorr}$, anode potential of $600-700 \mathrm{~V}$, current to the anode of $4-30 \mathrm{~mA}$, substrate at ground or floating potential, ion current to substrate of $0.4-8 \mathrm{~mA}$, substrate temperature of $150-300{ }^{\circ} \mathrm{C}$, and duration of deposition of approximately $2.5 \mathrm{~h}$. Four depositions were carried out which are labeled A-D. All depositions were carried out with an equal flow rate of silane and tritium. The substrate in depositions A-C was grounded. In deposi- 
tion D it was held at floating potential. The substrate temperature in depositions A and B was 300 and $225^{\circ} \mathrm{C}$, respectively, and in depositions $\mathrm{C}$ and $\mathrm{D}$ the temperature was $150{ }^{\circ} \mathrm{C}$.

\section{B. Tritium concentration}

A schematic of the thermal desorption apparatus, which was used to measure the tritium content of $a-\mathrm{Si}: \mathrm{H}: \mathrm{T}$ films, is shown elsewhere. ${ }^{20}$ The measurement procedure involved ramping the temperature of an $a-\mathrm{Si}: \mathrm{H}: \mathrm{T}$ sample, which is in a quartz tube having an argon purge flow rate of 100 normal $\mathrm{cm}^{3} / \mathrm{min}$, at a rate of $5{ }^{\circ} \mathrm{C} / \mathrm{min}$ to $900{ }^{\circ} \mathrm{C}$, soaking at this temperature for $9 \mathrm{~h}$, and then returning the sample to room temperature. Tritium evolution in the form HTO (oxide) is absorbed by the first silica gel trap (trap A), while tritium evolution in the form HT (elemental) is absorbed by the second silica gel trap (trap B). In the latter case the elemental tritium, as part of the humidified argon stream, is oxidized in a copper furnace of $700{ }^{\circ} \mathrm{C}$ prior to entering the second silica gel trap. At the conclusion of the thermal cycle, the tritium content in silica gel traps A and B is determined using liquid scintillation counting. The atomic tritium concentration in the sample is defined as $N_{\mathrm{T}} /\left(n_{\mathrm{Si}} A t\right)$, where $N_{\mathrm{T}}, n_{\mathrm{Si}}, A$, and $t$ are the total (oxide and elemental associated) number of tritium atoms, silicon atom density, sample area, and film thickness, respectively. The thickness of the film is determined using a profilometer. A background test without the presence of a tritiated sample preceded the above described measurement, thereby ensuring no residual tritium was included in the accounting. The instantaneous total tritium concentration in the argon stream is measured with an in-line ionization chamber tritium monitor.

\section{Tritium effusion}

Unlike conventional hydrogen effusion experiments requiring ultrahigh vacuum and mass spectrometer systems, tritium effusion experiments are carried out by measuring the evolution of tritium in an argon-filled ionization chamber. Tritium effusion experiments are carried out in a modified ionization tritium monitor. ${ }^{18}$ A schematic of tritium effusion monitoring is shown in Fig. 1. Tritium effusion monitor consists of three regions: the sample holder, the ion precipitator, and the ion chamber proper. The sample holder consists of a copper crucible, heated with a boron-nitride coated graphite heater, and two thermocouples, one in the copper crucible close to the sample and the other on top of the crucible. The ion precipitator consists of three grids, each with $\sim 70 \%$ open area, between the sample holder and the ion chamber. The ion precipitator, with its outer grids at ground potential and its central grid at $100 \mathrm{~V}$ dc, ensures that any gaseous species (effused molecules or prevailing argon atmosphere) entering the ion chamber is electrically neutral. Owing to the emission of tritium decay betas from the tritiated sample as well as the tritium present in the effused species, there is continual production of charged species through ionization in the volume space immediately above the sample. This charge is swept out by the electric field in the ion precipitator region. Thus, the ion precipitator serves to eliminate any stray

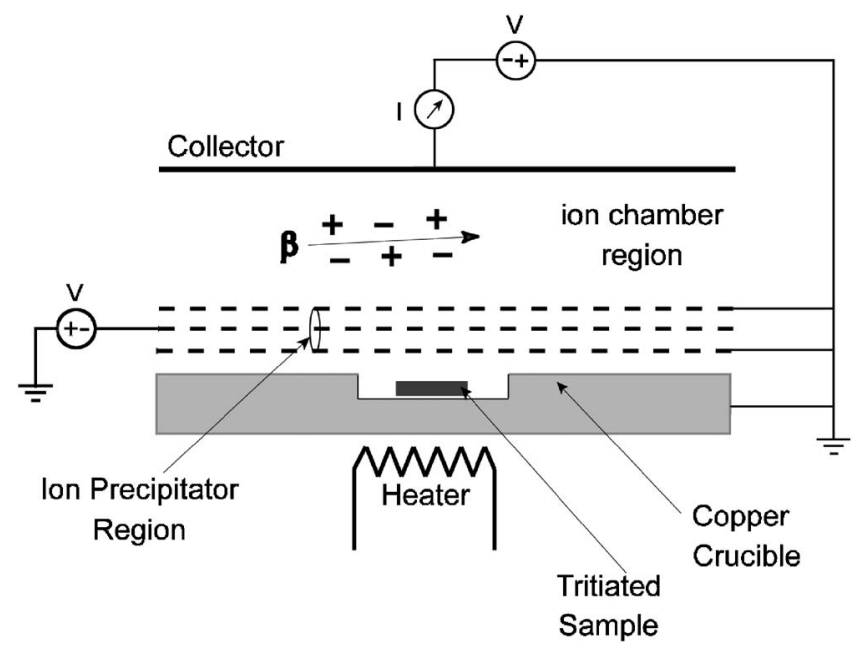

FIG. 1. Illustration of tritium effusion monitoring.

contribution to the ion chamber signal. The ion chamber consists of a grounded cylindrical chamber, $1 \mathrm{~L}$ in net volume, and a collector which is held at $-100 \mathrm{~V} \mathrm{dc}$. A fraction of the tritium in the effused HT molecules in the ion chamber undergo radioactive decay, emitting beta particles with an average energy of $5.7 \mathrm{keV}$, and lead to the production of electron-ion pairs through ionization of the argon atmosphere. The electron-ion pairs, under the influence of the electric field in the ion chamber, drift towards the anodecathode, and thus produce the measured current. The electric field is sufficiently strong that all ions are collected, and consequently the collector current is directly proportional to the number of tritium atoms in the ion chamber. The time derivative of the collector current is directly proportional to the rate of tritium effusion. Any error in the current signal due to ion-chamber-surface adsorption effects is negligible given that the total current signal is several orders of magnitude greater than the background signal, and that the surface memory outgassing effects for this monitor are small owing to the high polish of the internal surfaces of the chamber. A complete description of the operation of tritium ionization chambers is given elsewhere. ${ }^{18}$

A typical tritium effusion experiment involved placing an $a-\mathrm{Si}: \mathrm{H}: \mathrm{T}$ sample, approximately $1 \mathrm{~mm}^{2}$ in size, in the copper crucible, establishing an argon purge, evacuating the chamber, and then backfilling the chamber with argon to $1 \mathrm{~atm}$. The sample is subjected to linear temperature ramping from room temperature to approximately $900{ }^{\circ} \mathrm{C}$. Tritium effusion experiments were carried out at temperature ramp rates of $5,10,20$, and $40^{\circ} \mathrm{C} / \mathrm{min}$.

The concentrations of hydrogen and tritium in the films are expected to be in proportion to the ratio of hydrogen and tritium in the discharge chamber, owing to the high dissociation of gases in the dc-saddle field glow discharge. ${ }^{21}$ The evolution of hydrogen and tritium from the films is, to first order, assumed to be in proportion to their concentrations in the films. Since the collector current is due to only the number of tritium atoms present in the ion chamber, the tritium effusion monitor measures one-third of the total hydrogen evolved. 
TABLE I. Tritium content in $a$-Si: $\mathrm{H}: \mathrm{T}$ films.

\begin{tabular}{lcc}
\hline \hline & $\begin{array}{c}\text { Deposition C } \\
(\mathrm{A} 155)\end{array}$ & $\begin{array}{c}\text { Deposition D } \\
(\mathrm{A} 212)\end{array}$ \\
\hline HTO (in silica gel trap A) & $0.15 \mathrm{mCi}^{\mathrm{a}}$ & $0.02 \mathrm{mCi}$ \\
HT (in silica gel trap B) & $26.8 \mathrm{mCi}$ & $4.8 \mathrm{mCi}$ \\
Total T (traps A and B) & $27.0 \mathrm{mCi}$ & $4.8 \mathrm{mCi}$ \\
Total T (via time integration) & $30.0 \mathrm{mCi}$ & $5.0 \mathrm{mCi}$ \\
No. of T atoms (average), $N_{\mathrm{T}}$ & $5.9 \times 10^{17}$ & $10^{17}$ \\
Film thickness, $t$ & $0.81 \mu \mathrm{m}$ & $0.17 \mu \mathrm{m}$ \\
Film area (surface and edges), $A$ & $1.47 \mathrm{~cm}^{2}$ & $1.37 \mathrm{~cm}^{2}$ \\
Atomic fraction, $N_{\mathrm{T}} / N_{\mathrm{Si}}^{\mathrm{b}}$ & $9.9 \%$ & $8.6 \%$ \\
\hline \hline
\end{tabular}

${ }^{\mathrm{a}}$ millicurie $=3.7 \times 10^{7} \mathrm{dps}$.

${ }^{\mathrm{b}} N_{\mathrm{Si}} \approx t A n_{\mathrm{Si}}$, where $n_{\mathrm{Si}} \approx 5 \times 10^{22} \mathrm{~cm}^{-3}$

\section{Tritium outgassing at room temperature}

Two types of experiments were carried out to estimate the rate of tritium outgassing at room temperature from as deposited $a-\mathrm{Si}: \mathrm{H}: \mathrm{T}$ films. These experiments are denoted as dry tests and wet tests. The dry test involves the absorption of desorbed water from the films, both $\mathrm{H}_{2} \mathrm{O}$ and $\mathrm{HTO}$, by a desiccant, while the wet test involves the absorption of desorbed HTO, by liquid water, through isotopic swamping. These tests only measure the evolution of tritiated water from the films. However, considering that surfaces under ambient conditions are replete with water and hydroxyl ions, hydrogen outgassing from surfaces is essentially in the oxide form. ${ }^{22}$

The dry test involved suspending an $a-\mathrm{Si}: \mathrm{H}: \mathrm{T}$ sample in a sealed polypropylene bottle containing $\sim 200 \mathrm{~g}$ of silica gel, periodically analyzing the silica gel for the quantity of tritium absorbed, and thus determining the average rate of tritium outgassing over a given period. The quantity of tritium in each $200 \mathrm{~g}$ charge of silica gel is determined by leaching in $500 \mathrm{~mL}$ of agitated de-ionized water over a period of about $24 \mathrm{~h}$. The tritium concentration in the water is measured using liquid scintillation counting. The wet test, on the other hand, involved suspending an $a-\mathrm{Si}: \mathrm{H}: \mathrm{T}$ sample in a sealed polypropylene bottle containing $250 \mathrm{~mL}$ of deionized water, periodically withdrawing two $1 \mathrm{~mL}$ samples of the water, using a syringe, and determining the cumulative quantity of tritium as a function of time. The average rate of tritium outgassing over a given period was determined by taking the time derivative of this data. The initial atmosphere in the polypropylene bottles was ambient air.

\section{RESULTS AND DISCUSSION}

\section{A. Tritium concentration}

Tritium concentrations in $a-\mathrm{Si}: \mathrm{H}: \mathrm{T}$ films prepared in deposition C (sample A155) and deposition D (sample A212) are shown in Table I. The large ratio of HT to HTO evolution is consistent with the fact that virtually all hydrogen effusion occurs at sufficiently high temperatures when the surface is free of water and hydroxyl ions, that is, atomic hydrogen diffusing to the surface recombines and desorbs as elemental hydrogen. The total tritium content as determined through time integration of the tritium concentration in the argon stream ${ }^{16}$ is in agreement with the total tritium content of the

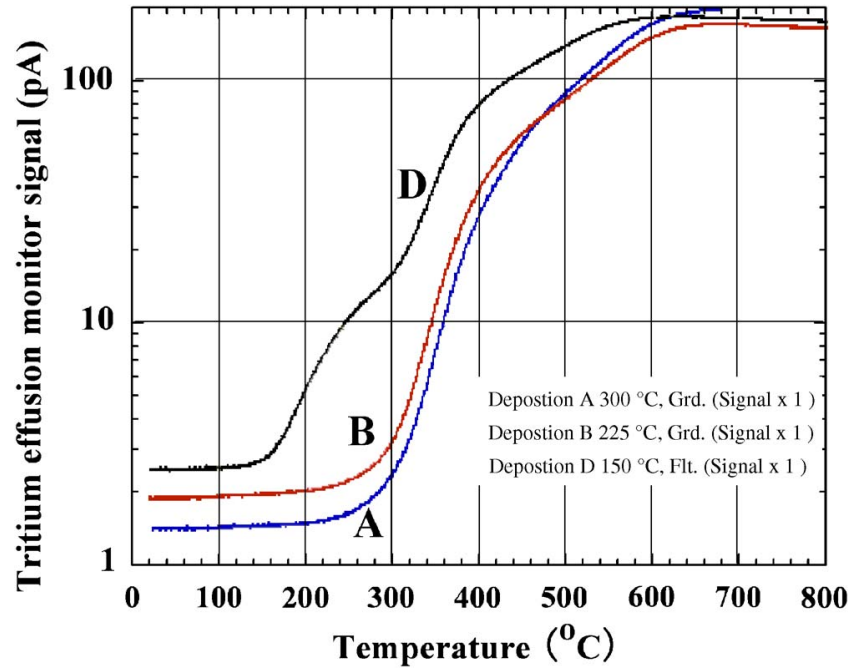

FIG. 2. (Color online) Hydrogen evolution from $a$-Si:H:T films of depositions $\mathrm{A}, \mathrm{B}$, and $\mathrm{D}$ as a function of temperature (linear temperature ramp rate: $\left.5^{\circ} \mathrm{C} / \mathrm{min}\right)$

two silica gel traps (A and B). The atomic concentration of tritium in the two samples is $9.9 \%$ and $8.6 \%$, respectively.

Similar samples from these two depositions (sample A170 from deposition C and sample A206 from deposition D) were analyzed using FTIR spectroscopy for hydrogen and tritium content. Computing the integrated absorption strength of the stretching modes of hydrogen around $2000 \mathrm{~cm}^{-1}$, along with the appropriate calibration factor, ${ }^{4}$ the atomic concentrations of hydrogen in the two samples were determined to be $22 \%$ and $15 \%$, respectively. The atomic concentration of tritium is then inferred from the product of the ratio of the integrated intensities of the stretching modes of tritium to hydrogen over the oscillator strengths and the atomic concentration of hydrogen. The ratios of the stretching modes, absorption of $\mathrm{Si}-\mathrm{T}$ around $1250 \mathrm{~cm}^{-1}$ to that of $\mathrm{Si}-\mathrm{H}$ around $2000 \mathrm{~cm}^{-1}$, were determined to be 0.42 for deposition $\mathrm{C}$ and 0.62 for deposition D. For both samples the atomic concentration of tritium is $9.3 \%$, which is within $10 \%$ of the desorption measurements. Additionally, the ratio of tritium to hydrogen is approximately $1: 2$, which is the proportion of $\mathrm{T}$ to $\mathrm{H}$ in the discharge chamber.

\section{B. Tritium effusion}

The cumulative tritium evolved and the tritium effusion rate as a function of the sample temperature are shown in Figs. 2 and 3, respectively. These profiles show that significant tritium evolution occurs only when the sample temperature exceeds the growth temperature. At temperatures below the growth temperature, but above room temperature, there is an increase in the tritium monitor signal by about $100 \mathrm{fA}$, which is equivalent to a tritium concentration change of $100 \mathrm{pCi} / \mathrm{cm}^{3}$ in a monitor volume of $1 \mathrm{~L}$. Assuming that this evolution is predominantly due to tritium on the surface of the sample, a surface tritium concentration of about $10 \mu \mathrm{Ci} / \mathrm{cm}^{2}$ is obtained, which is equivalent to 2.1 $\times 10^{14}$ (tritium)at. $/ \mathrm{cm}^{2}$ or about $6.7 \times 10^{14}$ (hydrogen) at./ $\mathrm{cm}^{2}$. The hydrogen evolved here is of the order of a monolayer. 


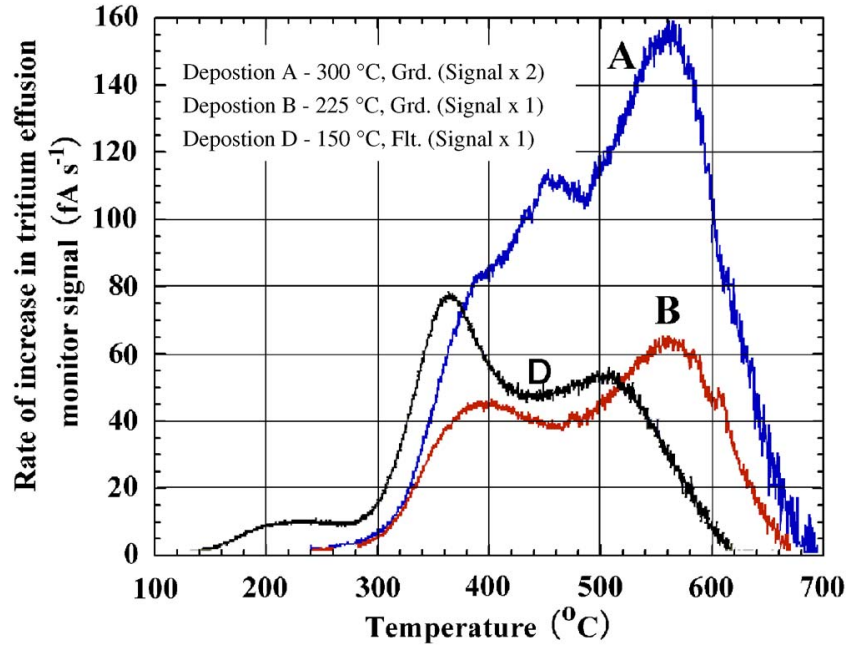

FIG. 3. (Color online) Hydrogen effusion rate profiles for $a-\mathrm{Si}: \mathrm{H}: \mathrm{T}$ films of depositions $\mathrm{A}, \mathrm{B}$, and $\mathrm{D}$ as a function of temperature (linear temperature rate: $\left.5^{\circ} \mathrm{C} / \mathrm{min}\right)$.

Typical effusion profiles in Fig. 3 show the presence of several peaks which are suggestive of different hydrogen bonding configurations in silicon. To further identify the temperature position of these peaks, an empirical approach of Gaussian deconvolution is employed to analyze the profiles. A summary of the data is provided in Table II. Three peaks are observed and identified as high temperature peak HT and low temperature peaks LT1 and LT2. The effusion peaks obtained here are similar to those reported in the literature for hydrogen and deuterium. The appearance of the LT peaks suggests the presence of an interconnected void structure. The low temperature peak at about $453{ }^{\circ} \mathrm{C}$ is somewhat unusual, suggesting possible film liftoff.

The effusion profile represents the evolution of molecular hydrogen that occurs due to a series of rate processes. ${ }^{6}$ Studies in the literature suggest that HT evolution is rate limited by diffusion of atomic hydrogen in $a$-Si, while LT evolution is limited by surface desorption of molecular hydrogen from void rich $a$-Si. ${ }^{5,23-26}$ The desorption energy can be determined by applying the following surface desorption rate equation to the low temperature peaks:

TABLE II. Range of maximum temperatures for the tritium effusion peaks for $a-\mathrm{Si}: \mathrm{H}: \mathrm{T}$ samples prepared under various conditions.

\begin{tabular}{|c|c|c|c|}
\hline & $\begin{array}{l}T_{m}\left({ }^{\circ} \mathrm{C}\right) \\
\mathrm{LT} 2^{\mathrm{a}} \text { peak }\end{array}$ & $\begin{array}{l}T_{m}\left({ }^{\circ} \mathrm{C}\right) \\
\mathrm{LT} 1^{\mathrm{a}} \text { peak }\end{array}$ & $\begin{array}{l}T_{m}\left({ }^{\circ} \mathrm{C}\right) \\
\text { HT }^{\mathrm{a}} \text { peak }\end{array}$ \\
\hline $\begin{array}{l}\text { Deposition } \mathrm{A}^{\mathrm{b}} \\
\left(300^{\circ} \mathrm{C} \text {, ground }\right)\end{array}$ & $383-424$ & $453-487$ & $558-593$ \\
\hline $\begin{array}{l}\text { Deposition } \mathrm{B}^{\mathrm{c}} \\
\left(225^{\circ} \mathrm{C} \text {, }\right. \\
\text { ground })\end{array}$ & $\ldots$ & $395-459$ & $536-638$ \\
\hline $\begin{array}{l}\text { Deposition } \mathrm{D}^{\mathrm{c}} \\
\left(150^{\circ} \mathrm{C},\right. \\
\text { floating })\end{array}$ & $228-283$ & $364-419$ & $492-600$ \\
\hline
\end{tabular}

${ }^{\mathrm{a}} \mathrm{LT}$ : low temperature; HT: high temperature.

${ }^{\mathrm{b}}$ Ramp rates: 5,10 , and $20^{\circ} \mathrm{C} / \mathrm{min}$.

${ }^{c}$ Ramp rates: $5,10,20$, and $40{ }^{\circ} \mathrm{C} / \mathrm{min}$.
TABLE III. Free energy of desorption of molecular hydrogen as determined from the LT1 and LT2 peaks.

\begin{tabular}{lcc}
\hline \hline & $\begin{array}{c}\Delta G(\mathrm{eV}) \\
\text { for the LT1 peak }\end{array}$ & $\begin{array}{c}\Delta G(\mathrm{eV}) \\
\text { for the LT2 peak }\end{array}$ \\
\hline $\begin{array}{l}\text { Deposition A } \\
\left(300^{\circ} \mathrm{C}, \text { ground }\right)\end{array}$ & 2.09 \\
$\begin{array}{l}\text { Deposition B } \\
\left(225^{\circ} \mathrm{C}, \text { ground }\right)\end{array}$ \\
$\begin{array}{l}\text { Deposition D } \\
\left(150^{\circ} \mathrm{C}, \text { floating }\right)\end{array}$ \\
\hline \hline$\frac{d\left(N / N_{0}\right)}{d t}=\left(\frac{k T}{h}\right)\left[1-\left(\frac{N}{N_{0}}\right)\right]^{n} \exp (-\Delta G / k T)$,
\end{tabular}

where $N$ and $N_{0}$ represent the hydrogen evolved from the sample and the initial hydrogen in the sample, respectively, $T$ is the sample temperature, $n$ is the order of the reaction, $\Delta G=\Delta H+T \Delta S$ is the free energy of desorption, $\Delta H$ is the enthalpy of reaction, $\Delta S$ is the entropy of reaction, and $k$ and $h$ are the Boltzmann and Planck constants, respectively. ${ }^{5,23}$ Applying this rate equation to both the LT1 and LT2 peaks by plotting $\ln \left\{d\left(N / N_{0}\right) / d t(k T / h)^{-1}\left[1-\left(N / N_{0}\right)\right]^{-n}\right\}$ as a function of $1 / T$ results in a straight line for $n=1$, which indicates that the desorption reaction is a first order rate process. The fitting was carried out over a temperature range equal to the full width at half maximum of the desorption peak, symmetrically about the peak temperature. In each instance, the correlation coefficient exceeded 0.98. A summary of the inferred free energy of desorption, evaluated at the peak temperature, is given in Table III. The results shown represent averages of data obtained from several experiments carried out at various ramp rates on samples from a given deposition. The desorption energy obtained from LT1 and LT2 peaks is of the order of $2 \mathrm{eV}$, which is consistent with the literature values. ${ }^{5,6,23}$

With respect to the evolution of hydrogen at high temperature, an estimate of the diffusion coefficient of hydrogen is determined by following Beyer and Wagner. ${ }^{24}$ The analysis proceeds on the basis of the time-dependent Fick's diffusion equation. The calculations ignore any mass effect due to tritium. The analyzed data for $a-\mathrm{Si}: \mathrm{H}: \mathrm{T}$ films from depositions A, B, and D are presented in Fig. 4. A least squares fit of the diffusion data yields a hydrogen diffusion activation energy of $1.69 \mathrm{eV}$ and a diffusion coefficient preexponent of $0.0096 \mathrm{~cm}^{2} / \mathrm{s}$. The diffusion coefficient, as determined by Beyer and Wagner, is also shown in Fig. $4 .^{5}$ The results obtained here show that the diffusion coefficient is about an order of magnitude smaller than that obtained by Beyer and Wagner. This is due to the larger activation energy obtained here, $1.69 \mathrm{eV}$ as opposed to $1.5 \mathrm{eV}$. The difference in the hydrogen diffusion activation energy, which cannot be accounted for by the mass effect of tritium, is attributed to significant densification of the material structure. It is noteworthy that most reported literature data are for samples showing the HT effusion peak only. In contrast, the HT peak in this work is retarded due to the appearance of the LT peak which perhaps serves to densify the film. 


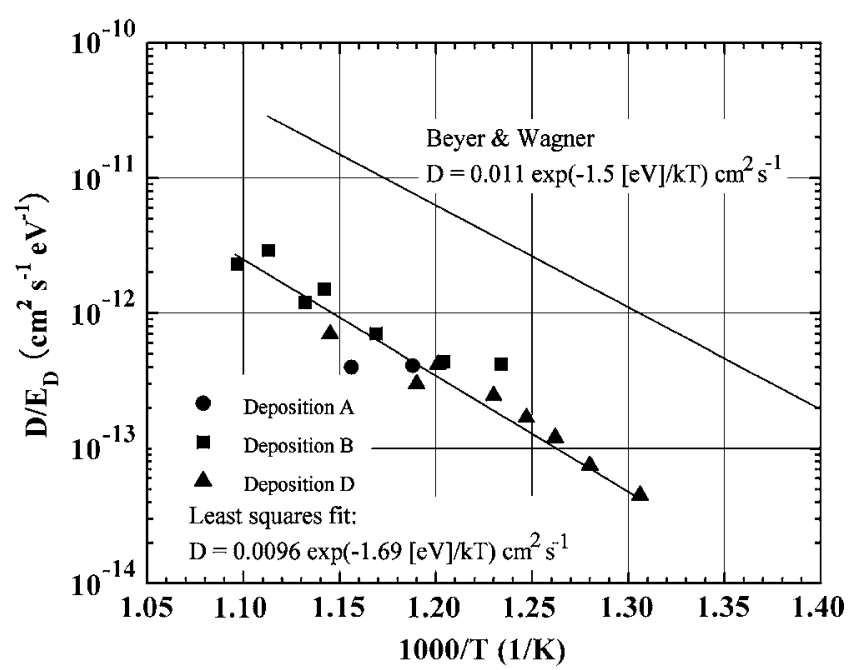

FIG. 4. Plot of $D / E_{D}=\left(d^{2} \beta\right) /\left(\pi^{2} k T_{m}^{2}\right)$ as a function of $1 / T=1 / T_{m}$, where $D$ $\left(\mathrm{cm}^{2} / \mathrm{s}\right)$ is the hydrogen diffusion coefficient, $E_{D}(\mathrm{eV})$ is the hydrogen diffusion activation energy, $d(\mathrm{~cm})$ is the film thickness, $\beta(\mathrm{K} / \mathrm{s})$ is the linear temperature ramp rate, $T_{m}(\mathrm{~K})$ is the position of the HT evolution peak, and $k$ is the Boltzmann constant.

The effusion profiles suggest that the films in this study are void rich. To learn more about the structural character of the films, FTIR analysis of the samples was carried out. The fractional peak areas for specific vibrational modes representing different hydrogen bonding configurations are summarized in Table IV. Vibrational mode at $2000 \mathrm{~cm}^{-1}$ represents the stretching mode of $\mathrm{SiH}$, while the vibrational mode at $2100 \mathrm{~cm}^{-1}$ represents stretching mode of $\mathrm{SiH}_{2}$ dihydrides, $\left(\mathrm{SiH}_{2}\right)_{\mathrm{n}}$ dihyride chains, and $\mathrm{SiH}$ surface hydrogen (hydrogenated voids or clusters). The results show that the microstructure parameter ranges from 0.16 to 0.76 . The sample prepared at $225^{\circ} \mathrm{C}$ has the least proportion of $\mathrm{SiH}_{2}$. This observation correlates with the general observation that films deposited close to this temperature are of device quality. The vibrational modes at 845 and $880-890 \mathrm{~cm}^{-1}$ represent the $\mathrm{SiH}_{2}$ wagging and scissor modes. Determination of the ratio of these doublet modes to the mode at $2100 \mathrm{~cm}^{-1}$ provides an indication of the presence of hydrogenated voids. The doublet to $2100 \mathrm{~cm}^{-1}$ ratios is seen to be relatively high for all the samples (the smallest value is 0.44 ). This suggests the presence of a void structure even for samples prepared above $300{ }^{\circ} \mathrm{C}$, which is generally in agreement with the results of the effusion tests. FTIR spectra also showed oxidation signal

TABLE IV. Fractional peak areas of specific vibrational modes representing different hydrogen bonding configurations for $a-\mathrm{Si}: \mathrm{H}: \mathrm{T}$ samples prepared under different deposition conditions.

\begin{tabular}{|c|c|c|}
\hline & 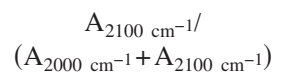 & $\begin{array}{c}\left(\mathrm{A}_{845 \mathrm{~cm}^{-1}}+\mathrm{A}_{880-890 \mathrm{~cm}^{-1}}\right) \\
\mathrm{A}_{2100 \mathrm{~cm}^{-1}}\end{array}$ \\
\hline $\begin{array}{l}\text { Deposition A } \\
\left(300{ }^{\circ} \mathrm{C} \text {, ground }\right)\end{array}$ & 0.27 & 0.44 \\
\hline $\begin{array}{l}\text { Deposition B } \\
\left(225^{\circ} \mathrm{C} \text {, ground }\right)\end{array}$ & 0.16 & 0.77 \\
\hline $\begin{array}{l}\text { Deposition C } \\
\left(150^{\circ} \mathrm{C} \text {, ground }\right)\end{array}$ & 0.60 & 0.78 \\
\hline $\begin{array}{l}\text { Deposition D } \\
\left(150^{\circ} \mathrm{C} \text {, floating) }\right.\end{array}$ & 0.76 & 0.47 \\
\hline
\end{tabular}

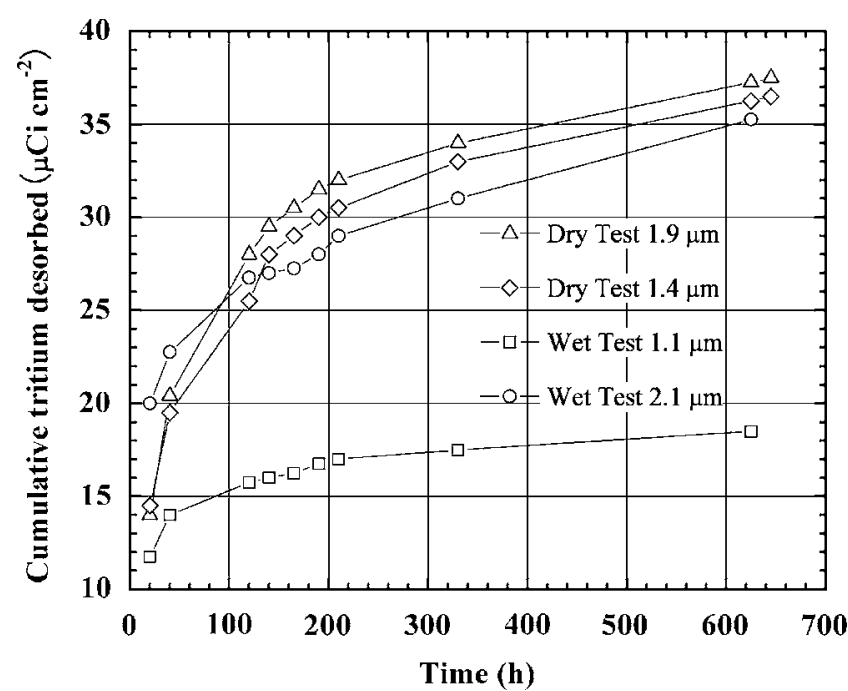

FIG. 5. Cumulative tritium desorption from $a$-Si:H:T films of deposition C with time at room temperature.

around $950-1150 \mathrm{~cm}^{-1}$ for long-term stored $a-\mathrm{Si}: \mathrm{H}$ samples. Secondary ion mass spectroscopy measurements show an oxide layer of a few nanometers for $a$-Si: $\mathrm{H}$ samples stored for a few months.

\section{Tritium outgassing}

The cumulative tritium desorbed from the four samples of deposition $\mathrm{C}$ is shown in Fig. 5. Two of the samples were subjected to the dry test and the other two to the wet test. The differences in the film thicknesses are attributed to nonuniformities at the growth surface of each discrete sample. The tritium data show that after approximately $600 \mathrm{~h}$ of outgassing, the total quantity of tritium desorbed from each of the samples is less than $40 \mu \mathrm{Ci} / \mathrm{cm}^{2}$. This is equivalent to total hydrogen desorption of about $8.4 \times 10^{14}$ at. $/ \mathrm{cm}^{2}$. Alternatively, this is about $0.2 \%$ of the hydrogen content in the sample. The measured cumulative tritium desorption under dry and wet conditions are of the same order of magnitude, the noise in the data is likely due to experimental error. These results indicate that the desorption of tritium in the two tests is in the oxide form, and that the film surfaces are sufficiently replete with water and hydroxyl ions in both the dry and wet environments. This is consistent with the fact that on the average the lowest water vapor pressure above the silica gel is of the order of $10^{-6}$ atm or $1 \mathrm{ppm}$. The thinnest sample, having a film thickness of $1.1 \mu \mathrm{m}$, measures about half the tritium of the other three thicker samples. This thickness effect is attributed to the void rich structure of the films, where the increase in internal void area with thickness contributes to increased outgassing.

The rate of tritium outgassing for the four samples at room temperature is shown in Fig. 6. The rate of outgassing is comparable for samples in dry and wet atmospheres. The $a$-Si:H:T samples show an initial outgassing rate of the order of $200 \mathrm{pCi} \mathrm{cm}^{-2} \mathrm{~s}^{-1}$. This is equivalent to total hydrogen desorption rate of about $4.2 \times 10^{9}$ at. $\mathrm{cm}^{-2} \mathrm{~s}^{-1}$. After about $600 \mathrm{~h}$ of outgassing the tritium outgassing rate appears to approach an asymptotic value of less than $10 \mathrm{pCi} \mathrm{cm}^{-2} \mathrm{~s}^{-1}$. This is equivalent to total hydrogen desorption rate of about 


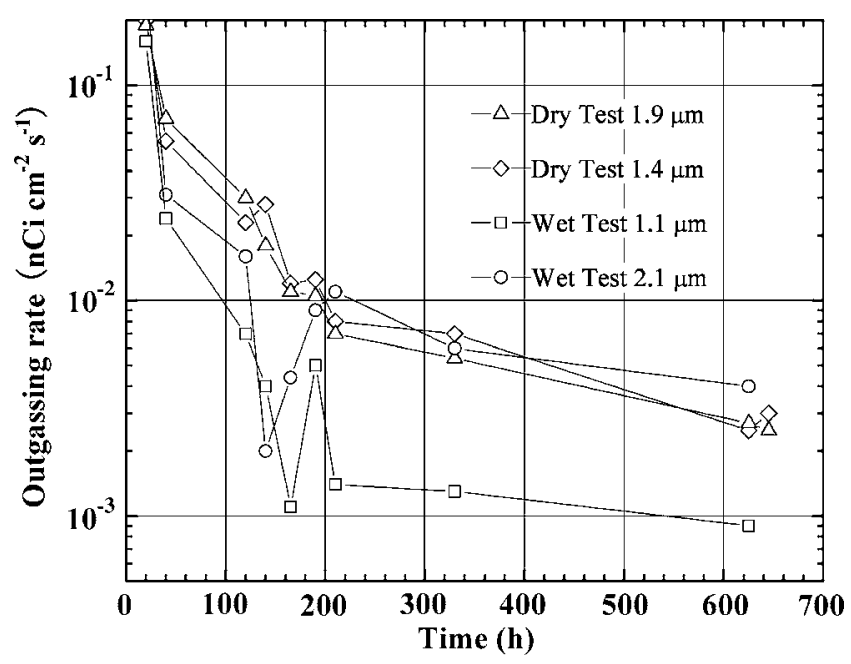

FIG. 6. Rate of tritium outgassing from $a$-Si:H:T films of deposition C with time at room temperature.

$2.1 \times 10^{8}$ at. $\mathrm{cm}^{-2} \mathrm{~s}^{-1}$. Assuming that hydrogen outgassing proceeds undiminished at the asymptotic rate, more than 60 years would be required to lose half the hydrogen from the void network of the sample at room temperature. This "void network hydrogen diffusion" half-life in $a-\mathrm{Si}: \mathrm{H}$ samples reported here is about five times the tritium decay half-life.

Figure 6 suggests that there are two rate determining steps for the observed outgassing. Initially the desorption occurs at a higher rate and then, following a transition, at a lower asymptotic rate. Chemical reactions and gas desorption processes near a surface usually follow first order kinetics. ${ }^{6}$ It is proposed that the observed tritium outgassing can be described by an exponential association relation,

$$
N=N_{1}\left[1-\exp \left(-t / \tau_{1}\right)\right]+N_{2}\left[1-\exp \left(-t / \tau_{2}\right)\right]
$$

where $N$ is the cumulative tritium (HTO) evolved, $N_{1}$ and $N_{2}$ are the source concentrations of tritium supporting the fast and slow outgassing, respectively, and $\tau_{1}$ and $\tau_{2}$ are time constants that characterize the two processes. Least squares fitting of the experimental data (the four curves in Fig. 5) to Eq. (2) yielded in each instance a correlation coefficient which exceeded 0.99. A summary of the fitted parameters is given in Table V. The time constant for the fast outgassing ranges from 9 to $23 \mathrm{~h}$, and the corresponding source concentrations of tritium range from 13.4 to $21.4 \mu \mathrm{Ci} / \mathrm{cm}^{2}$, which is equivalent to two to three monolayers of tritium. With respect to the slow outgassing process, the quantity of source tritium ranges from 5.3 to $20.6 \mu \mathrm{Ci} / \mathrm{cm}^{2}$, which is equiva-

TABLE V. Summary of results from the least squares fitting of the cumulative tritium outgassing measurements to the association relation $N=N_{1}(1$ $\left.-e^{-t / \tau}\right)+N_{2}\left(1-e_{2}^{-t / \tau}\right)$.

\begin{tabular}{lcccc}
\hline \hline & $N_{1}\left(\mu \mathrm{Ci} / \mathrm{cm}^{2}\right)$ & $\tau_{1}(\mathrm{~h})$ & $N_{2}\left(\mu \mathrm{Ci} / \mathrm{cm}^{2}\right)$ & $\tau_{2}(\mathrm{~h})$ \\
\hline Dry test, $1.4 \mu \mathrm{m}$ & 21.44 & 23.04 & 16.77 & 217.9 \\
Dry test, $1.9 \mu \mathrm{m}$ & 16.32 & 14.14 & 20.55 & 179.9 \\
Wet test, $2.1 \mu \mathrm{m}$ & 21.88 & 9.712 & 16.87 & 403.9 \\
Wet test, $1.1 \mu \mathrm{m}$ & 13.36 & 10.86 & 5.327 & 200.0 \\
\hline \hline
\end{tabular}

lent to one to three monolayers of tritium. The time constant for the slow outgassing process ranges from 180 to $404 \mathrm{~h}$. The fast outgassing time constant varies from a few hours to less than a day, while the slow outgassing process takes 20 times longer. The two processes suggest differences in the physical steps leading to the observed outgassing.

It has been recognized that hydrogenated amorphous silicon oxidizes immediately upon exposure to air at a rate which depends on the microstructure of the film. ${ }^{27}$ The oxidation process overall results in $\mathrm{SiO}_{2}, \mathrm{SiO}$, and $\mathrm{H}_{2} \mathrm{O}$ (HTO) by dehydrogenation of the surface. The oxide thickness increases with the square root of the exposure time, indicative of an oxygen diffusion limited process. ${ }^{28}$ Assuming that the fast outgassing process is essentially complete within the first $60 \mathrm{~h}$ (approximately three time constants), the resulting oxide layer thickness is estimated to be approximately three monolayers or 8-9 $\AA^{28}$ At the conclusion of the outgassing experiments reported here, that is, $600 \mathrm{~h}$, the oxide layer thickness is estimated to be $\sim 18 \AA$. In view of the foregoing, we infer that the observed tritium outgassing involves surface desorption from an oxidized silicon surface, where the effective surface area of the film includes the interconnected voids given the large void fraction in the samples examined here.

Assuming that the outgassing process is limited by surface desorption of water molecules, the desorption kinetics can be described by the surface desorption rate equation [Eq. (1)]. Here, $N$ and $N_{0}$ represent the concentration of HTO molecules evolved from the film and initially present, respectively. Assuming that the desorption follows first order kinetics and substituting $N=N_{0}[1-\exp (-t / \tau)]$ into Eq. (1), the desorption free energy is derived to be $\Delta G=k T \ln (k T \tau / h)$. Using an average time constant of $15 \mathrm{~h}$ for the fast outgassing process, and a room temperature of $300 \mathrm{~K}$, a free energy of $1.04 \mathrm{eV}$, or $96.5 \mathrm{~kJ} / \mathrm{mol}$, is obtained. Proost et al. report desorption energies of $23 \mathrm{~kJ} / \mathrm{mol}$ for physisorbed water and 55-202 kJ/mol for chemisorbed water on the surface of silicon oxide. ${ }^{29}$ The free energy obtained here indicates that the initial tritium outgassing represents desorption of tightly bonded water from an oxidized surface of the $a-\mathrm{Si}: \mathrm{H}$ film.

As for the slow outgassing process, if we assume that this process is also limited by a surface desorption reaction, as described by Eq. (2), then using the time constant of 200-300 h yields a free energy of $1.11-1.12 \mathrm{eV}$. This free energy, which falls within the range of reported values in the literature, is approximately $10 \%$ larger than that obtained for the fast outgassing process, i.e., $1.04 \mathrm{eV}$. The increase in the free energy of desorption suggests the presence of another rate limiting mechanism.

If we now assume that the additional limiting process is diffusion of oxygen through the oxide layer to the tritium rich amorphous silicon-silicon oxide interface, an estimate of the diffusivity of oxygen can be inferred. Using the slow outgassing time constant of 200-300 h and oxide thickness of $9 \AA$ from above, we obtain an oxygen diffusion coefficient $\left(D \sim L^{2} / \tau\right)$ of $1 \times 10^{-20}-0.8 \times 10^{-20} \mathrm{~cm}^{2} / \mathrm{s}$, respectively. This value compares reasonably well with 2 $\times 10^{-20} \mathrm{~cm}^{2} / \mathrm{s}$ oxygen diffusivity in oxidized hydrogenated amorphous silicon reported by Ponpon and Bourdon. ${ }^{28}$ 
It is worth noting that the above described tritium outgassing experiments detect HTO, which appears to represent essentially all the desorbed tritium. Considering that the surface of the films are replete with adsorbed water and hydroxyl radicals, ion exchange reactions likely contribute to the formation and hence desorption of HTO. ${ }^{22}$

As a final point, the above results of outgassing measurements likely represent the hydrogen stability in the $a$-Si:H material where the lowest hydrogen stability is expected. As suggested by the effusion and FTIR measurements, the films obtained in the study are void rich especially for those deposited at low temperature. The samples used in the outgassing measurement were deposited at a substrate temperature of $150{ }^{\circ} \mathrm{C}$ and they certainly contain interconnected voids.

\section{CONCLUSIONS}

The radioactive property of tritium is used to study hydrogen bonding and surface kinetics of hydrogenated amorphous silicon. Tritium thermal effusion experiments are carried out using an ionization chamber at atmospheric pressure. The results correspond to those reported in the literature for hydrogen and deuterium effusion, where the latter are obtained by employing ultrahigh vacuum and mass spectrometry. Tritium effusion data, along with FTIR measurements, suggest that the material examined here is rich in voids. From the effusion data a surface desorption energy similar to that reported in the literature is obtained. A diffusion activation energy of $1.69 \mathrm{eV}$ is measured, which results in a lower diffusion coefficient compared to literature values. This is attributed to densification of the films. The effusion experimental results demonstrate the viability of tritium effusion monitoring as a diagnostic for effusion studies in tritiated $a-\mathrm{Si}: \mathrm{H}$.

Long-term tritium outgassing of tritiated hydrogenated amorphous silicon in air at room temperature is investigated by measuring the evolution of tritiated water (HTO). Experimental results suggest that at room temperature hydrogen evolution from $a-\mathrm{Si}: \mathrm{H}: \mathrm{T}$ films is from the surface and its large void network. Tritium outgassing follows first order kinetics and is described by two rate limiting processes. The first process, fast outgassing, is described by surface desorption of HTO, while the second process, slow outgassing, appears to be limited by oxygen diffusivity in the growing oxide layer on amorphous silicon. A free energy of $1.04 \mathrm{eV}$ is obtained for the desorption of HTO chemisorbed on oxidized amorphous silicon. This value falls within the range of reported values of $0.6-2.2 \mathrm{eV}$. An oxygen diffusivity of $0.8-1 \times 10^{-20} \mathrm{~cm}^{2} / \mathrm{s}$ in silicon oxide on $a-\mathrm{Si}: \mathrm{H}$ is estimated. These values compare reasonably well with the reported value of $2 \times 10^{-20} \mathrm{~cm}^{2} / \mathrm{s}$. The samples used in the outgassing measurement were deposited at low temperature $\left(150{ }^{\circ} \mathrm{C}\right)$ and had a void rich structure. The results may indicate the outgassing limit for the film with lowest hydrogen stability. More than 60 years would be required to lose half the hydrogen from the void network of the sample at room temperature.

${ }^{1}$ R. A. Street, Technology and Applications of Amorphous Silicon (Springer-Verlag, Berlin, 2000).

${ }^{2}$ W. E. Spear and P. G. Lecomber, Solid State Commun. 17, 1193 (1975).

${ }^{3}$ W. E. Spear and P. G. Lecomber, Philos. Mag. 33, 935 (1976).

${ }^{4}$ T. M. Searle, Properties of Amorphous Silicon and its Alloys (INSPEC, London, 1998).

${ }^{5}$ W. Beyer, Physica B 170, 105 (1991).

${ }^{6}$ W. Beyer, Sol. Energy Mater. Sol. Cells 78, 235 (2003).

${ }^{7}$ L. S. Sidhu, T. Kosteski, S. K. O’Leary, F. Gaspari, S. Zukotynski, N. P. Kherani, and W. T. Shmayda, Mater. Res. Soc. Symp. Proc. 420, 509 (1996).

${ }^{8}$ L. S. Sidhu, T. Kosteski, F. Gaspari, S. Zukotynski, N. P. Kherani, and W. T. Shmayda, Mater. Res. Soc. Symp. Proc. 467, 129 (1997).

${ }^{9}$ L. S. Sidhu, T. Kosteski, S. Zukotynski, and N. P. Kherani, J. Appl. Phys. 85, 2574 (1999).

${ }^{10}$ N. P. Kherani, T. Kosteski, S. Zukotynski, and W. T. Shmayda, Fusion Technol. 28, 1609 (1995).

${ }^{11}$ T. Kosteski, N. P. Kherani, F. Gaspari, S. Zukotynski, and W. T. Shmayda, J. Vac. Sci. Technol. A 16, 893 (1998).

${ }^{12}$ T. Kosteski, F. Gaspari, F. Hum, S. Costea, S. Zukotynski, N. P. Kherani, and W. T. Shmayda, Mater. Res. Soc. Symp. Proc. 609, A30.1 (2000).

${ }^{13}$ S. Costea, F. Gaspari, T. Kosteski, S. Zukotynski, N. P. Kherani, and W. T. Shmayda, Mater. Res. Soc. Symp. Proc. 609, A27.4 (2000).

${ }^{14}$ N. P. Kherani, S. Zukotynski, and W. T. Shmayda, US Patent No. 5,118,951 (2 June 1992).

${ }^{15}$ N. P. Kherani, S. Zukotynski, and W. T. Shmayda, US Patent No. 5,606,213 (25 February 1997).

${ }^{16}$ T. Kosteski, N. P. Kherani, P. Stradins, F. Gaspari, W. T. Shmayda, L. S. Sidhu, and S. Zukotynski, IEE Proc.: Circuits Devices Syst. 150, 274 (2003).

${ }^{17}$ T. Kosteski, N. P. Kherani, P. Stradins, F. Gaspari, W. T. Shmayda, L. S. Sidhu, and S. Zukotynski, LLE Review 95, 196 (2003).

${ }^{18}$ N. P. Kherani and W. T. Shmayda, Fusion Technol. 21, 340 (1992).

${ }^{19}$ D. O. Stodilka, N. P. Kherani, W. T. Shmayda, and S. Thorpe, Int. J. Hydrogen Energy 25, 1129 (2000).

${ }^{20}$ T. Kosteski, "Tritiated Amorphous Silicon Films and Devices," Ph.D thesis, University of Toronto, 2001.

${ }^{21}$ P. K. Lim, F. Gaspari, and S. Zukotynski, J. Appl. Phys. 78, 5307 (1995).

${ }^{22}$ W. T. Shmayda, A. B. Antoniazzi, and R. A. Surette, Thermal Desorption Spectroscopy as an Investigative Technology for Studying Surface Bound Tritium, Ontario Hydro Research Division Report No. 92-51-K (1992).

${ }^{23}$ J. A. Mcmillan and E. M. Peterson, J. Appl. Phys. 50, 5238 (1979).

${ }^{24}$ W. Beyer and H. Wagner, J. Appl. Phys. 53, 8745 (1982).

${ }^{25}$ N. Sridhar, D. D. L. Chung, W. A. Anderson, and J. Coleman, J. Electron. Mater. 24, 1451 (1995).

${ }^{26}$ W. Beyer and U. Zastrow, J. Non-Cryst. Solids 230, 880 (1998).

${ }^{27}$ R. A. Street, Hydrogenated Amorphous Silicon (Cambridge University Press, Cambridge, 1991).

${ }^{28}$ J. P. Ponpon and B. Bourdon, Solid-State Electron. 25, 875 (1982).

${ }^{29}$ J. Proost, M. Baklanov, K. Maex, and L. Delaey, J. Vac. Sci. Technol. B 18, $303(2000)$ 